\title{
Environmental predictors of foraging and transit behaviour in flatback turtles Natator depressus
}

\author{
Michele Thums ${ }^{1, *}$, David Waayers ${ }^{2}$, Zhi Huang ${ }^{3}$, Chari Pattiaratchi ${ }^{4}$, Jeffrey Bernus ${ }^{1,5}$, \\ Mark Meekan ${ }^{1}$
}

\begin{abstract}
${ }^{1}$ Australian Institute of Marine Science, Indian Ocean Marine Research Centre (M096), University of Western Australia 35 Stirling Highway, Crawley, Western Australia 6009, Australia

${ }^{2}$ Imbricata Environmental, PO Box 299, Northbridge, Western Australia 6865, Australia

${ }^{3}$ National Earth and Marine Observations Branch, Geosciences Australia, GPO Box 378, Canberra, Australian Capital Territory 2601, Australia

${ }^{4}$ School of Civil, Environmental and Mining Engineering and UWA Oceans Institute (M470), University of Western Australia, 35 Stirling Highway, Crawley, Western Australia 6009, Australia

${ }^{5}$ Present address: Parc national de la Guadeloupe, Montérant, Saint Claude, 97120 Guadeloupe, FWI
\end{abstract}

\begin{abstract}
Sea turtles migrate between nesting beaches and foraging grounds, but little is known about the cues they use to direct these migrations, and the habitats that define their foraging grounds. Here, we used satellite telemetry to follow the movements of 11 flatback turtles Natator depressus after nesting on islands in the waters off the coast of the Kimberley region of northern Australia. State-space models were used to objectively define inter-nesting, migration and foraging behaviour during the $327 \pm 315 \mathrm{~d}$ (mean $\pm \mathrm{SD}$ ) that the turtles were tracked. These animals migrated along the coast in water depths of $63 \pm 5 \mathrm{~m}$ to foraging grounds on the mid-Sahul Shelf in the Timor Sea in average water depths of $74 \pm 12 \mathrm{~m}, 135 \pm 35 \mathrm{~km}$ from shore. Distribution modelling showed that flatback turtles preferred foraging and transiting in clear waters (suspended material $<0.06 \mathrm{~g} \mathrm{~m}^{-3}$ ), 60 to $90 \mathrm{~m}$ deep and in association with complex, benthic geomorphology (banks, shoals, terraces, deep holes and valleys) thought to support a high abundance of sessile invertebrates, the likely targets of their foraging. Distance to the tidal front was also a strong predictor of turtle migratory behaviour, with the animals potentially following tidal fronts along the Kimberley coast. Our study identified both critical habitats for this species and the environmental variables that predict their migration and foraging. This information is important to aid spatial planning of conservation for this data-deficient species that is endemic to northern Australia.
\end{abstract}

KEY WORDS: Satellite tracking $\cdot$ Telemetry $\cdot$ Lacepede Islands $\cdot$ Kimberley $\cdot$ State-space model $\cdot$ Inter-nesting $\cdot$ Migration $\cdot$ Sahul Shelf $\cdot$ Key ecological feature $\cdot$ Tidal fronts

\section{INTRODUCTION}

Knowledge of the ecology of a species is central to the implementation of effective conservation strategies. It is particularly important for the assessment of any effects of anthropogenic activities, because these must be identified against a background of variability in the biophysical environment and cli-

\footnotetext{
${ }^{*}$ Corresponding author: m.thums@aims.gov.au
}

mate change. For many species, biotelemetry offers the only practical means to obtain quantitative information about distribution, behaviour and habitat use across their ranges (Cooke 2008), and a key issue is how this data can be used to implement informed conservation management (Hays et al. 2016).

The relatively recent development of state-space modelling approaches for the analysis of telemetry

() The authors 2017. Open Access under Creative Commons by Attribution Licence. Use, distribution and reproduction are unrestricted. Authors and original publication must be credited. 
data on animal movement provides a robust statistical framework that can both account for observation error and infer behavioural states (Costa et al. 2012, Jonsen et al. 2013). Use of such models combined with the integration of environmental data sets allows us to move beyond interpretations that simply depict where animals go in an environment to explore the variables that influence their movement patterns in marine environments. Importantly, the objective determination of behavioural states can identify biologically important areas and equally, provide objective designation of marine protected areas so that they encompass key sites used by vulnerable species (Hays 2014).

This combination of telemetry methods and statespace modelling approaches to data analysis is now being used to understand the ecology of marine megafauna that inhabit pelagic environments, such as marine reptiles, cetaceans and sharks (Costa et al. 2012). In some cases, the progress of this field is driven by potential for conflicts between megafauna and industry, particularly projects exploiting offshore oil and gas resources. Such developments may expose these megafauna to a number of pressures related to industrial construction and operation (Pendoley 2005, Waayers et al. 2011), including noise and vibration, habitat modification, vessel movements, and marine discharges. These issues are of particular concern for megafauna because they tend to have life history traits that make them vulnerable to population declines, such as low rates of reproduction, long lives and slow growth rates (Hays et al. 2016).

Flatback turtles Natator depressus exemplify these issues. Endemic to Australia and restricted to northern Australia, significant rookeries for the species exist along the northern coast of Western Australia, a region where there is ongoing development of large oil and gas reserves both across and beyond the continental shelf. Recognition of the potential for conflict with industry has led to relatively largescale tagging projects over the last 2 decades, the results of which have recently begun to be published (see Waayers et al. 2011, 2015, Pendoley et al. 2014b, Whittock et al. 2014, 2016). Although these studies have provided much needed information on the spatial components of the migration of flatback turtles, there is a paucity of information on the drivers of patterns of movement and residency, especially residency associated with foraging (as opposed to nesting).

Frontal zones, where vertical mixing enhances productivity in pelagic ecosystems (Lefevre 1986, Olson et al. 1994) are known to be strong drivers of movement ecology of many species of marine megafauna, including marine turtles (Polovina et al. 2000, Polovina et al. 2001, Block et al. 2011). These mostly occur near the edge of the continental shelf or in oceanic waters and, unlike most other sea turtles, flatback turtles tend to remain within the boundary of the northern Australian continental shelf (Limpus et al. 2013, Waayers et al. 2015) in waters that appear to be less than $130 \mathrm{~m}$ deep (Whittock et al. 2014). However, frontal zones do also occur within these shelf habitats, particularly in areas where large tides interact with strong solar heating and evaporation (Simpson \& Hunter 1974). Similar to pelagic frontal zones, these tidal fronts are distinctive oceanographic features that mark the boundaries between water bodies with different physical characteristics, where there is localised and sometimes vigorous vertical movement of water that can enhance local productivity (Lefevre 1986, Olson et al. 1994). The northern coastal shelves on which they occur also have a complex biological oceanography and geomorphological setting. Adjacent to the coast, the input of terrigenous sediments and estuarine systems create gradients of turbidity and habitat types across the shelf. Spread along and across the shelf are banks, coral reefs, shoals, canyons and terraces, the legacies of changes in sea level with successive ice ages, carbonate seeps and coral growth. Thus, the movement patterns of flatback turtles occur within a dynamic environment where multiple benthic and pelagic factors may drive patterns of foraging and migration. At present, the only information we have on the distributions of the species on these coastal shelves is qualitative and suggests a preference for shallow, turbid, inshore waters (Limpus et al. 1983), and associations with soft bottom habitats, 6 to $35 \mathrm{~m}$ deep (Limpus et al. 2013).

Our study used animal-borne satellite transmitters to document movement patterns of flatback turtles from the Lacepede Islands, in the Kimberley region of Western Australia, during the inter- and post-nesting periods. We then used state-space models to objectively identify foraging grounds and migratory pathways, and determine the key physical (e.g. tidal fronts, turbidity) and habitat (e.g. geomorphology, sediment type) variables that influence the movement patterns of these animals as they leave the rookery. We also quantified the area used in each behavioural mode (foraging, nesting, transiting) to quantitatively identify these biologically important areas and assess how well the existing system of marine reserves encompasses these areas. 


\section{MATERIALS AND METHODS}

\section{Study site}

The Lacepede Islands lie on the Kimberley Shelf (Fig. 1), a region characterised by a large tidal range $(\sim 10 \mathrm{~m})$ and weak wind forcing in the absence of tropical cyclones (Church \& Craig 1998). The region is subject to the Australasian monsoon with westerly winds from December to March and southeasterly (trade) winds from April to November. The westerly winds result in a net drift of water to the northeast. When the winds relax, this water flows along the shelf as the Holloway Current (D'Adamo et al. 2009).

\section{Animal tagging}

An Argos-linked Fastloc GPS transmitter was attached to each of 11 female flatback sea turtles nesting on West Lacepede Island (16 $\left.51.3^{\prime} \mathrm{S} 122^{\circ} 8.2^{\prime} \mathrm{E}\right)$ between 2 to 4 December 2009 (6 turtles) and 9 to 10 February 2010 (5 turtles) (Table 1). Of the transmitters, 10 (F4G 291A) were manufactured by Sirtrack (Havelock North) and 1 (Mk10-AF; 53244) by Wildlife Computers (Redmond).

Turtles were caught as they were returning to the ocean after nesting and were placed on a $0.5 \mathrm{~m}$ high rectangular container over which a turtle harness was draped. The design of the harness was based on that of Sperling \& Guinea (2004) and was composed of a moulded polypropylene base plate, straps made from $22 \mathrm{~mm}$ wide seatbelt webbing with Velcro ends and a centralised plastron ring with raised nodules to reduce the potential for snagging. Satellite tags were fixed to a base plate using a fast-curing marine adhesive/sealant and stainless steel screws, and coated with antifouling paint (Longlife Antifouling Blue, International Paint, Queensland). The transmitter was positioned over the top of the second central scute and harness lines were threaded through the tag base plate, tightened, then fixed into place by the Velcro strips and $2.5 \mathrm{~mm}$ diameter wire crimped over the harness lines and tightened with pliers. Flipper tags were attached to the front flippers of each turtle and the curved carapace length (CCL) and curved carapace width (CCW) were measured using a flexible measuring tape.

All transmitters relayed position information via the Argos satellite network (www.ARGOS-system. org). Position acquisition was attempted every hour for the GPS and every $40 \mathrm{~s}$ for Argos when turned on and the saltwater switch was dry. The transmitters were programmed to transmit continuously for the first $90 \mathrm{~d}$ and then for $12 \mathrm{~h}$ every $72 \mathrm{~h}$. The Mk10-AF transmitter also relayed summaries of dive depth, maximum dive depth, dive duration and temperature binned within 14 user-defined data ranges. A dive was only logged if it was deeper than $1 \mathrm{~m}$ and longer than $20 \mathrm{~s}$.

\section{Movement behaviour}

The Bayesian state-space switching model developed by Jonsen et al. $(2003,2005)$ was fitted to each individual turtle track to account for observation error, to regularise position estimates and to provide behavioural state estimation. As GPS positions were more sparse and less frequent than Argos positions (see Fig. S1 in the Supplement at www.int-res.com/ articles/suppl/n032p333_supp.pdf), we fitted the statespace switching model to pooled Argos and GPS data sets. The observation error for each Argos estimate was as per the reported error associated with each Argos location class (B, A, 0, 1, 2, 3) and we set the GPS position error at the best Argos location class (3; within $150 \mathrm{~m}$ ). The precision of GPS locations varies within an individual track, depending on the number of satellites used to calculate each location. Here, the mean number of satellites used was $5 \pm 1$ (mean \pm SD), with trials showing that when 5 GPS satellites are used, $50 \%$ of locations were within $29 \mathrm{~m}$ and $95 \%$ within $165 \mathrm{~m}$ of the true position (Dujon et al. 2014).

The model identified 2 discrete behavioural modes from these data: transient and resident. Although the latter behaviour is often associated with foraging (Kareiva \& Odell 1987), it can also occur when animals are resting or breeding (Bailey et al. 2008, 2009).

The state-space switching models were fitted via Markov chain Monte Carlo (MCMC) implemented in JAGS 3.2.0 (Plummer 2003) called from $R$ (R Development Core Team 2016) using the R package bsam (Jonsen et al. 2013). We ran 2 MCMC chains of length 120000 , of which the initial 80000 were discarded, and every 40th of the remaining samples were retained. We used a $6 \mathrm{~h}$ time step for all turtles. All models were checked for convergence using the methods outlined by Jonsen et al. (2013).

Using the 2 movement behaviours identified by the state-space model (resident and transient), we categorised 4 different behavioural modes in the tracks: inter-nesting, outward transit, foraging and transit (as distinct from outward transit). Inter-nesting was identified as the time between the start of the deployment and the switch to transient behaviour. Outward transit 



Fig. 1. State-space position estimates of flatback sea turtles. Each track is colour-coded by behavioural mode: red: resident; black: transient. Turtle ID is indicated on the bottom right and duration of the deployment (d) in the top right of each map. Maps show bathymetry and the coast of northwestern Australia, Timor to the north and Melville Island on the top right. The $1000 \mathrm{~m}$ contour is at the boundary between blue and green, and the boundary between the yellow and green is approximately $70 \mathrm{~m}$. The Lacepede Islands are marked $(\star)$. The main features of the Sahul and Kimberley Shelves are marked on the first map: Londonderry Rise (Lon Rise), Bonaparte Depression (Bon Dep), Adele Mavis Bank (AMB) and Van Diemen Rise (V D Rise) 
turtle to the mean deployment length for that mode, to ensure that individuals with short deployments were given equal representation to those with long deployments. For the utilisation density calculated for the foraging mode and all modes combined, the data were subsampled to the minimum deployment length for deployments greater than 1 yr. For turtles that had deployment lengths less than $1 \mathrm{yr}$, the original data were used, as for these individuals the migration was not complete thus tracks might not have been representative of foraging or total home ranges.

\section{Environmental variables}

A total of 26 environmental variables (Table S1) encompassing a range of physical, oceanographic and geochemical factors that had the potential to influence foraging and transiting of flatback turtles were included in the analysis.

We identified the location of tidal fronts (the boundary between mixed and stratified conditions), which was predicted by calculating values of the expression $\log \left(h / u^{3}\right)$, where $h$ is the water depth and $u$ is the maximum tidal current amplitude (Simpson \& Hunter 1974). Many studies show that tidal fronts occur when $\log \left(h / u^{3}\right)=2.7$ (Simpson 1981, Nahas et al. 2005). The tidal amplitudes were derived from a numerical model developed for Australia and described by Haigh et al. (2014). The depth-averaged barotropic hydrodynamic model was configured for the entire Australian coastline using the Danish Hydraulic Institute's Mike21 flexible mesh (FM) suite of modelling tools. The Mike21 FM modelling system is based on the numerical solution of the incompressible Reynolds-averaged Navier-Stokes equations invoking the assumptions of Boussinesq and hydrostatic pressure. The model grid had a resolution of $\sim 10 \mathrm{~km}$ along the entire coastline of mainland Australia, Tasmania and surrounding islands, and was validated using tide gauges. We used both the Simpson-Hunter value and the distance to the tidal front as predictor variables.

\section{Modelling environmental drivers of movement}

We chose boosted decision tree techniques, available in the DTREG software, to model the relationship between movement behaviour and environmental variables. This method was selected owing to its robustness for modeling non-linear species-environment relationships, and its ability to identify impor- tant variables (e.g. Elith et al. 2006, Huang et al. 2011, 2012). As foraging and transit behaviour are likely to be driven by different environmental variables, each behaviour was modelled separately. Only outward transit was included when modelling transitory movements.

To reduce potential spatial autocorrelation among both foraging and outward transit position estimates, we selected only those that were at least $5 \mathrm{~km}$ away from their nearest neighbours as inputs to the models. These positions were regarded as the presence records. To develop the models, 10000 and 15000 pseudo-absence samples were generated from 2 spatial domains; inshore and offshore of the positions estimates, respectively (Fig. S2). Again, we selected only pseudo-absence positions that were at least $5 \mathrm{~km}$ away from their nearest neighbours for the modelling.

Values of the 26 environmental variables (Table S1) at each of the foraging and outward transit presence locations and the pseudo-absence locations from each of the modeling domains (inshore and offshore) were extracted. We then modeled probability of presence during foraging and outward transit in each of the 2 modeling domains, thus resulting in 4 distribution models. The final numbers of samples for each of the 4 models are listed in Table 2. Exploratory analyses were then used to reduce the number of predictors for the models. First, for each environmental variable, the ratio between its standard deviation and mean was calculated. If the ratio was smaller than 0.2 , indicating insufficient variation across the modelling domain, we deemed that the corresponding environmental variable was not a suitable predictor. Second, the pairwise correlations (Pearson's coefficient, $\rho$ ) were calculated among the environmental variables, where a $|\rho|$ value greater than 0.7 indicated a strong correlation. In such cases, the 2 environmental variables in the pair contained redundant information and 1 was removed from further analysis. The results of the 2 exploratory analyses were combined with some expert judgement to select the final sets of predictors for the 4 models (Table S1). The same set of parameters was

Table 2. Number of samples in each of 4 models. Probability of turtle presence during outward transit behaviour $(\mathrm{T})$ and foraging behaviour $(\mathrm{F})$ where pseudo-absences were taken

from an inshore domain (I) and an offshore domain (O)

\begin{tabular}{|lcccc|}
\hline & T-I & F-I & T-O & F-O \\
\hline Presence & 228 & 1055 & 228 & 1055 \\
Pseudo-absence & 827 & 2356 & 1064 & 3008 \\
\hline
\end{tabular}


used for all model runs. These included 1000 trees calculated with a tree depth of 5, a minimum of 10 samples for the node to continue splitting, automatic selection of the shrink factor, 100 trees to search predictors, and 10-fold cross-validation for testing and pruning of trees.

We used a manual iteration procedure to select the best combination of the predictors for each model. In the first iteration, only 1 predictor was added to the model. This was repeated for all predictors. The predictor that achieved the best model performance was retained for the next iteration. Each of the subsequent iterations added a different predictor to the model. The iteration procedure was terminated when the model performance either decreased or achieved only minor improvement. Two measures were used to evaluate the model performance: sensitivity and area under the receiver operating characteristic (ROC) curve (AUC). The sensitivity measure was used because we were interested in the presence rather than the absence of turtles. AUC is recommended as an overall measure that is not sensitive to the prevalence issue (Manel et al. 2001).

It is important to note that the aim of the modelling was not to predict the distribution of the flatback turtles. Instead, the primary objective was to identify key environmental variables driving movement patterns. In this study, these key environmental variables were identified through the variable importance scores $(\geq 50)$ that resulted from this modelling process. Owing to the interactions among selected predictors, partial species response curves could not be properly constructed. As an alternative, we used predicted probabilities of presence and pseudo-absence samples (Table 2) to construct the response curves (Huang et al. 2012). Input values of key environmental variables that were numeric were binned into equal intervals. A response curve was then constructed by plotting the mean predicted probabilities within these intervals ( $y$ axis) against the binned intervals ( $x$-axis). Similarly, for a key environmental variable that was categorical, we constructed a species response curve from the mean predicted probabilities of all categories.

We present grand means followed by the standard deviation.

\section{RESULTS}

\section{Movement behaviour}

The number of days for which transmitters provided data ranged from 16 to 831 , with a mean of $327 \pm 315$
(Table 1). Of the 11 turtles, 3 remained resident in the vicinity of the Lacepede Islands for the duration of their tag transmissions (47671: $126 d_{i}$ 47679: $199 d_{i}$ 47689: $24 \mathrm{~d})$. The remaining 8 individuals all moved in a northeasterly direction after leaving the islands (Fig. 1) and 3 of these did not switch behavioural modes after leaving (47680, 47677 and 53244) (Fig. 1a,b,d). The remaining 5 turtles spent $75 \pm 9 \%$ of their time in foraging mode, $7 \pm 3 \%$ in inter-nesting mode, $6 \pm 3 \%$ in outward transit and $16 \pm 5 \%$ in transit.

Of the 8 turtles that did not remain near the Lacepede Islands, 2 (47677 and 53244) left almost immediately after being tagged, while the remainder spent an average of $34.7 \pm 13.3 \mathrm{~d}$ resident around the islands, prior to switching to transit movements. Turtles tagged in December 2009 left the Lacepede Islands between 8 and 17 January 2010, whereas one tagged in early February 2010 departed on 21 of the same month (Table 1). During the inter-nesting phase, flatback turtles remained at an average distance of $15.75 \pm 12.25 \mathrm{~km}$ from West Lacepede Island, in water depths of $16 \pm 3 \mathrm{~m}$, with the core $50 \%$ utilisation distribution centred on the islands and encompassing $218.69 \mathrm{~km}^{2}$ (Fig. 2a, Table 3).

The turtles used a common pathway for their outward transit, following the $63 \pm 5 \mathrm{~m}$ depth contour between the relatively shallow inshore waters and the mid-shelf (Figs. 1a,b \& 2b, Tables $1 \& 3$ ). Of the 8 individuals that left the Lacepede Islands, 5 travelled around the north and 3 around the south of Adele Island during the transit (Figs. 1a,b \& 2b). These turtles spent $29.4 \pm 12.8 \mathrm{~d}$ in outward transit, $69 \pm 22 \mathrm{~km}$ from shore (Table 1), before arriving on the Sahul Shelf in the Timor Sea and switching to foraging behaviour. Search patterns were focused on the Sahul, Londonderry and Van Diemen Rises, and the Kimberley Shelf (Fig. 1a,b). Of the turtles, 2 (47682 and 47680) appeared to have a minor foraging area on the Adele Mavis Banks. There was some variation in this pattern among individuals, with 1 of the 5 (47678) foraging en route for $29 \mathrm{~d}$ after a short transit of $5 \mathrm{~d}$, before again switching to transit behaviour for another $17 \mathrm{~d}$. After reaching Van Diemen Rise (Fig. 1c), 300 km northwest of Darwin, it reverted to foraging behaviour for the remainder (387 d) of the tag deployment.

When in foraging mode, the turtles were $82 \pm$ $60 \mathrm{~km}$ from shore and in water depths of $53 \pm 26 \mathrm{~m}$ (Table 1). These grand mean values included the turtles with short deployments that foraged en route and those that foraged around the Lacepede Islands; however, when these turtles were excluded, the mean distance from shore averaged $109 \pm 57 \mathrm{~km}$ and water depths $65 \pm 25 \mathrm{~m}$ (Table 1). Of the 5 turtles with 

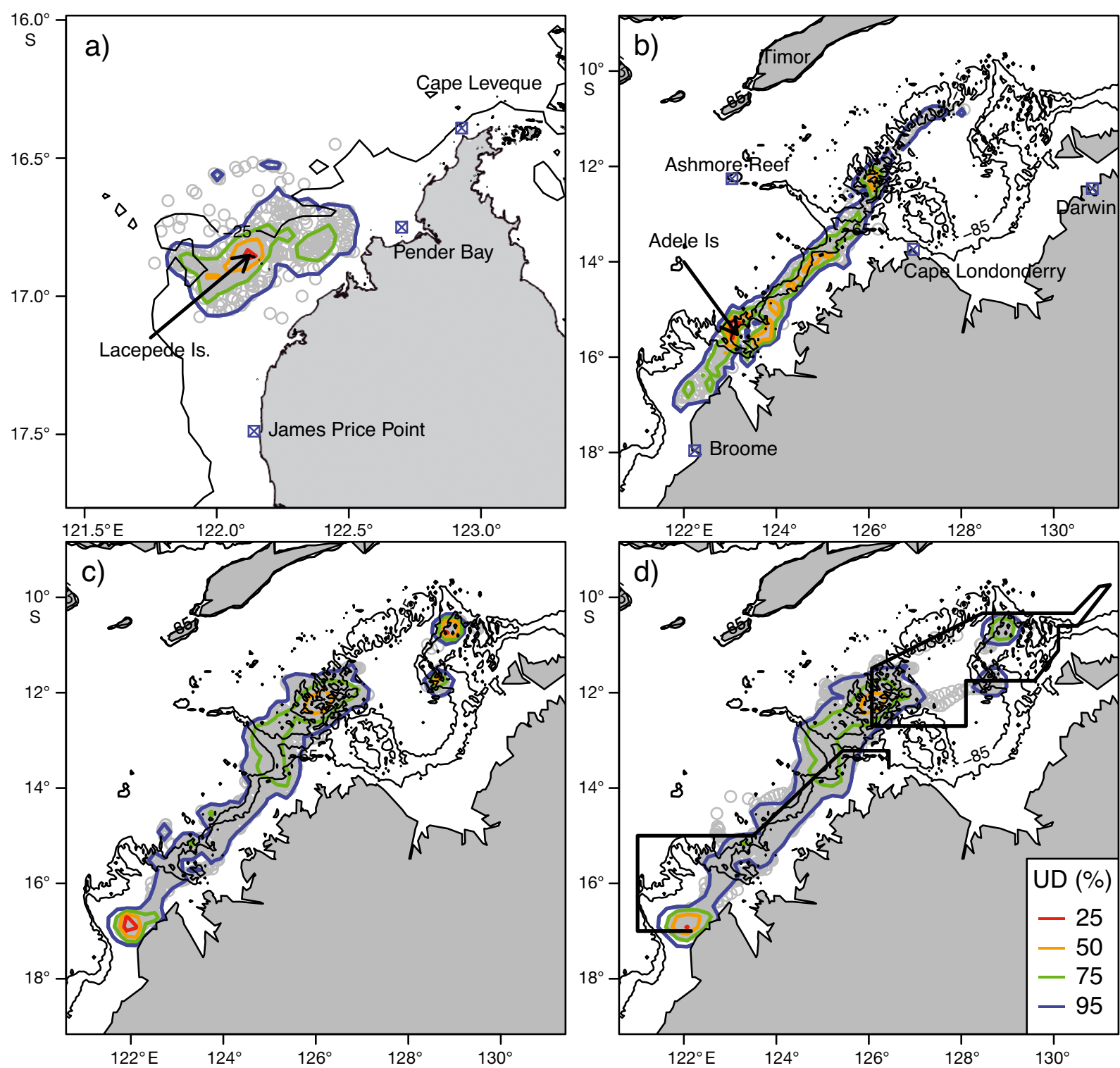

Fig. 2. The 25 (red), 50 (orange), 75 (green) and $95 \%$ (blue) kernel utilisation distribution of state-space position estimates $(0)$ for all flatback sea turtles during (a) the nesting season, showing the $25 \mathrm{~m}$ depth contour in dark grey; (b) the outward transit; (c) foraging; and (d) all behaviour modes combined. Also shown in thick black lines are 2 Commonwealth Marine Reserves: the Oceanic Shoals (top) and Kimberley (bottom). Dark grey contours on maps b, c and d show the $65 \mathrm{~m}$ and $85 \mathrm{~m}$ depth contours

multi-year deployments of tags, 2 (47678 and 47688) remained on the same foraging area (see Fig. S5 in the Supplement at www.int-res.com/articles/suppl/ n032p333_supp.pdf). However, the remaining 3 individuals made extensive movements along the coast, switching between foraging grounds.

\section{Home ranges}

The kernel utilisation distributions for pooled data sets are presented in Table 3 and Fig. 2. Apart from the Lacepede Islands, the turtles appeared to focus their foraging ( $50 \%$ KUD) on the Sahul Shelf, principally just to the east of the axis of the Londonderry Rise; $290 \mathrm{~km}$ southeast of Ashmore, on the Sahul Rise; $300 \mathrm{~km}$ directly east of Ashmore Reef at $12.24^{\circ} \mathrm{S}$, $126.15^{\circ} \mathrm{E}$; and on the Van Diemen Rise, $300 \mathrm{~km}$ northwest of Melville Island at $10.64^{\circ} \mathrm{S}, 128.90^{\circ} \mathrm{E}$ (Fig. 2c). These foraging grounds were approximately 22, 565, 699 and $1002 \mathrm{~km}$ from the Lacepede Islands, respectively. Two turtles (47670 and 47682) also foraged at the Adele Mavis Banks; however, this was not included as a core foraging area. Nesting 

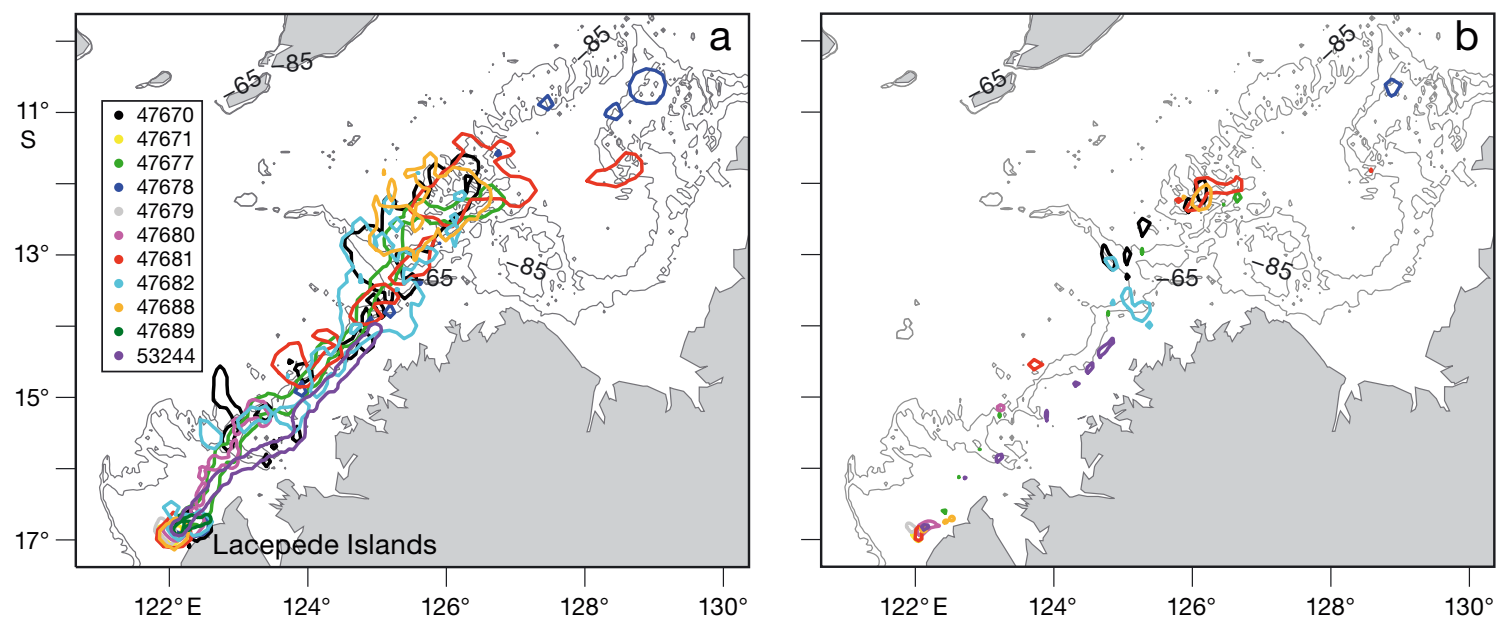

Fig. 3. (a) $95 \%$ and (b) $50 \%$ Brownian bridge kernel utilisation distribution of state-space position estimates for each of the flatback sea turtles. Grey lines show the $65 \mathrm{~m}$ and $85 \mathrm{~m}$ depth contours

Table 3. The 25, 50, 75 and $95 \%$ utilisation distribution in square kilometres calculated using the kernel density estimation method using state-space position estimates from all turtles combined for each behavioural mode (inter-nesting, outward transit, foraging) and all behavioural modes combined (all)

\begin{tabular}{|lrrrr|}
\hline \multirow{2}{*}{$\begin{array}{l}\text { Behaviour } \\
\text { mode }\end{array}$} & \multicolumn{5}{|c|}{ Utilisation distribution $\left(\mathrm{km}^{2}\right)-$} \\
\cline { 2 - 5 } & $25 \%$ & $50 \%$ & $75 \%$ & \multicolumn{1}{c|}{$95 \%$} \\
\hline Inter-nesting & 31.24 & 218.69 & 749.81 & 2030.74 \\
Outward transit & 3205.90 & 9261.49 & 20304.03 & 38114.59 \\
Foraging & 1918.95 & 9594.76 & 27824.79 & 70521.46 \\
All & 1153.16 & 8072.12 & 27675.83 & 72072.47 \\
\hline
\end{tabular}

Table 4 . The 25, 50, 75 and $95 \%$ utilisation distribution in square kilometres calculated using the Brownian bridge kernel method using state-space position estimates for each individual turtle (ID)

\begin{tabular}{|lrrrr|}
\hline \multirow{5}{*}{ ID } & \multicolumn{5}{c}{ Utilisation distribution $\left(\mathrm{km}^{2}\right)$} & \multirow{2}{*}{$55 \%$} \\
\cline { 2 - 5 } & $25 \%$ & $50 \%$ & $75 \%$ & \\
\hline 47670 & 115.08 & 388.40 & 949.42 & 2085.86 \\
47671 & 5.57 & 14.15 & 33.32 & 73.93 \\
47677 & 100.42 & 267.78 & 557.86 & 1138.04 \\
47678 & 0.00 & 0.00 & 141.67 & 543.05 \\
47679 & 4.83 & 12.78 & 30.12 & 77.85 \\
47680 & 14.86 & 53.86 & 144.85 & 412.27 \\
47681 & 0.00 & 181.14 & 656.62 & 1788.71 \\
47682 & 89.00 & 355.99 & 889.97 & 1919.78 \\
47688 & 43.88 & 190.13 & 511.90 & 1272.43 \\
47689 & 3.61 & 12.22 & 30.28 & 78.72 \\
53244 & 56.53 & 161.50 & 335.12 & 637.94 \\
Mean & 48.20 & 163.79 & 389.19 & 911.69 \\
\pm SD & \pm 44.37 & \pm 141.21 & \pm 344.67 & \pm 767.90 \\
Median & 43.88 & 171.32 & 335.12 & 637.94 \\
\hline \multicolumn{5}{c}{} \\
\cline { 2 - 5 } & & & & \\
\hline
\end{tabular}

grounds and migratory paths used by the turtles were largely within the Commonwealth Marine Reserves in this region, although foraging grounds were not well encompassed (Fig. 2d). The individual utilisation distributions provided by the Brownian bridge kernel density estimation method are shown in Table 4, and the 50 and $95 \%$ utilisation distributions presented in Fig. 3. These values were highly variable due to both short deployment lengths of tags on some individuals and the restriction of movements of some turtles to the area near the Lacepede Islands. The $50 \%$ utilisation distribution was relatively small for individual turtles $\left(163.78 \pm 141.21 \mathrm{~km}^{2}\right.$; Fig. 3b, Table 4$)$, but much larger when data sets were pooled among individuals $\left(8072.12 \mathrm{~km}^{2}\right.$; Fig. 2, Table 3). There was high overlap for the $95 \%$ utilisation distribution of all turtles (Fig. 3a), and 4 of the 5 turtles that travelled to the Timor Sea had overlapping $50 \%$ utilisation distributions on the Sahul Rise (Fig. 3b).

\section{Diving behaviour}

The turtle with the Mk10-AF transmitter (53244) had the shortest duration of deployment (16 d). For this animal, $30 \%$ of recorded dives were in the maximum depth bin of $50-100 \mathrm{~m}, 28 \%$ were in the maximum depth bin of $>20-50 \mathrm{~m}$ and $26 \%$ were in the maximum depth bin of 0-2 m (Fig. S4a). There was a greater proportion of dives recorded during daytime (Fig. S4). Similarly, the turtle spent the majority of its time $(15,28$ and $22 \%$, respectively) in these same depth bins and, with the exception of the smallest depth bin, it spent more time diving to the 2 deeper 
bins during the day (Fig. S4b). Approximately $27 \%$ of dives were of $20-30 \mathrm{~min}$ duration, $23 \%$ were of 30-40 min and $13 \%$ of 10-20 min (Fig. S4c). Nearly all dives were in waters from 30 to $35^{\circ} \mathrm{C}$ (Fig. S4d).

\section{Distribution models}

For the inshore modelling domain, water turbidity, as indicated by total suspended materials, was an important environmental factor influencing turtle presence with the highest variable importance scores (100 for transient behaviour and 96 for foraging behaviour) (Table 5). All flatback turtles preferred foraging and transiting in clear waters that had low total suspended material (e.g. $<0.06 \mathrm{~g} \mathrm{~m}^{-3}$ ) (Fig. 4a,d). The type of geomorphic feature was also very important for foraging behaviour (variable importance = 100), with a preference for terraces, and deep holes and valleys in the seabed (Figs. 4c \& 5a), whereas banks and shoals appeared to be more important for transiting turtles (Figs. 5b \& 6c). The presence of surface currents $>10 \mathrm{~cm} \mathrm{~s}^{-1}$ was associated with higher turtle presence when foraging (Fig. 4e, Table 5).

In the offshore modelling domain, water depth had the highest importance for both foraging and transiting (variable importance $=100$ ). Turtles foraged and transited in areas where water depths were less than

Table 5. Top ranked environmental variables selected by each of the 4 models where pseudo-absences were taken from both an inshore domain and an offshore domain, and turtle presence taken during outward transit behaviour and foraging behaviour

\begin{tabular}{|lc|}
\hline Variable & Importance score \\
\hline Outward transit, inshore domain & \\
Total suspended material & 100 \\
Gravel & 50 \\
Geofeature & 45 \\
Outward transit, offshore domain & \\
Depth & 100 \\
Gravel & 67 \\
Geofeature & 53 \\
Distance to tidal front & 50 \\
Foraging, inshore domain & \\
Geofeature & 100 \\
Total suspended material & 96 \\
Surface current velocity & 53 \\
Gravel & 37 \\
Foraging, offshore domain & 100 \\
Depth & 58 \\
Gravel & 32 \\
Distance to tidal front & \\
\hline
\end{tabular}

$100 \mathrm{~m}$, with a peak at around $20 \mathrm{~m}$ and another around $70 \mathrm{~m}$ depth (Fig. 6a,e). Sediment gravel content was also consistently selected in the models (Table 5), with the presence of turtles associated with gravel content between 15 and $45 \%$ (Figs. 4b \& 6b,f). Transiting turtles had a positive association with the tidal front (Figs. 6d \& S3), with the likelihood of their presence decreasing rapidly with increasing distance to the tidal front.

\section{DISCUSSION}

The combination of the analysis of telemetry data using a movement model with environmental data allowed us to objectively identify key habitats of flatback turtles and the environmental variables that influenced their outward transit and foraging behaviour. Prior to our study, the limited evidence available suggested associations with shallow, turbid, inshore waters (Limpus et al. 1983, 2013). Our analysis shows that this was not the case and that turtles moving from the Lacepede Islands were associated with clear water and some distance from shore (70 to $80 \mathrm{~km}$ ), with a high probability of presence in water depths of 60 to $90 \mathrm{~m}$. We also found movements to be related to benthic geomorphology of the Sahul Shelf, including deep holes and valleys, terraces, banks, and shoals.

Time series of tracking data were long enough to encompass 2 key behaviours of flatback turtles breeding and foraging - with many long tracks in excess of 1 yr and some beyond 2 yr. Consequently, we were able to identify and describe 3 critical aspects of the ecology of the species: (1) the spatial and temporal extent of the inter-nesting phase; (2) common migratory pathway along the $63 \mathrm{~m}$ depth contour off the Kimberley coast; and (3) the foraging grounds of these turtles on the Sahul Shelf, a region of banks, terraces and channels on the middle and outer shelf (Van Andel \& Veevers 1965). The complex geomorphology of the shelf is thought to support a high diversity of marine species that occur as a result of a combination of suitable substrates for settlement and growth of benthic invertebrates, and the channelling of water around banks and rises that increases current flow and mixing, enhancing local productivity (Brewer et al. 2007). The latter phenomenon may account for the relationship between the likelihood of the presence of turtles in foraging mode and current flow $>10 \mathrm{~cm} \mathrm{~s}^{-1}$. Of these variables, the strongest predictor of the presence of turtles in foraging mode was benthic geomorphology, notably terraces, deep holes and valleys. These habitats on the 

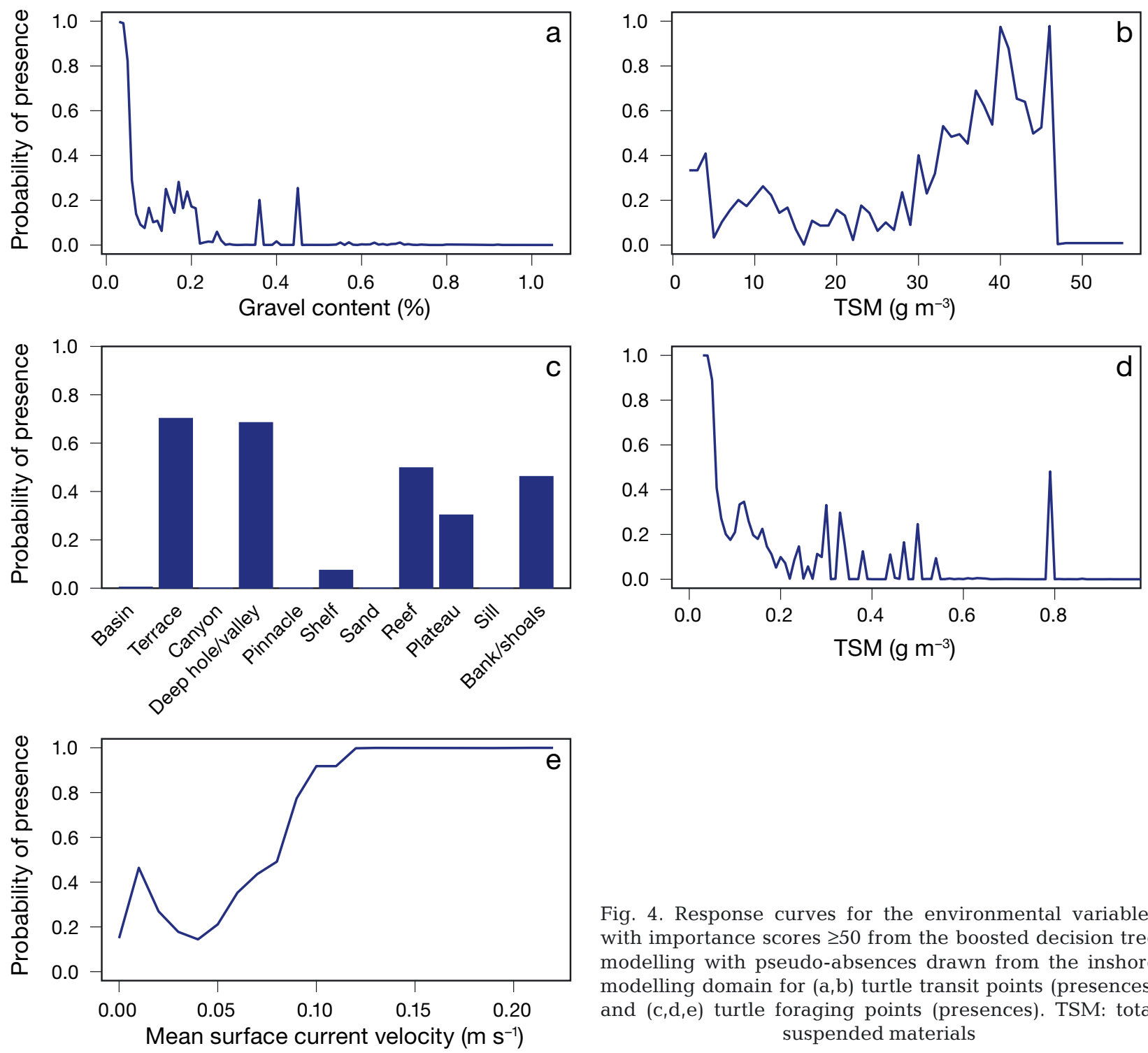

Sahul Shelf appear to enhance foraging habitat not just for flatback turtles from the Lacepede Islands rookery, but also for populations tagged at other rookeries (Barrow Island, Port Hedland, Mundabullangana) in Australia (Whittock et al. 2016), and for other species such as olive ridley Lepidochelys olivacea (McMahon et al. 2007, Whiting et al. 2007) and loggerhead turtles Caretta caretta (Waayers et al. 2015). Indeed, $20 \%(n=90)$ of flatback turtles satellite tagged in Western Australia travelled to the Sahul Shelf, suggesting this area is an important foraging area for marine turtles throughout the year (Waayers et al. 2015).

The feeding targets of flatback turtles are not known, as only very limited information is available on the diet of the species. Stomach contents from ani-

Fig. 4. Response curves for the environmental variables with importance scores $\geq 50$ from the boosted decision tree modelling with pseudo-absences drawn from the inshore modelling domain for $(\mathrm{a}, \mathrm{b})$ turtle transit points (presences) and $(\mathrm{c}, \mathrm{d}, \mathrm{e})$ turtle foraging points (presences). TSM: total suspended materials

mals stranded on the east coast of Australia and other observations suggest that the diet probably consists of benthic and pelagic invertebrates (Limpus et al. 1988, Zangerl et al. 1988), and given the association of foraging with complex geomorphology, benthic invertebrates seem a likely food source for individuals foraging on the Sahul Shelf.

Water depth was a strong predictor of both turtle outward transit and foraging behaviours, with peaks around $20 \mathrm{~m}$ and from 60 to $90 \mathrm{~m}$ depths. The shallow peak for transit behaviour was likely the result of the start of the transit of migrating individuals through shallow water from the Lacepede Islands out to the $\sim 63 \mathrm{~m}$ depth contour where, on average, most turtles were transiting. Foraging behaviour also peaked around $20 \mathrm{~m}$ depths, possibly due to 

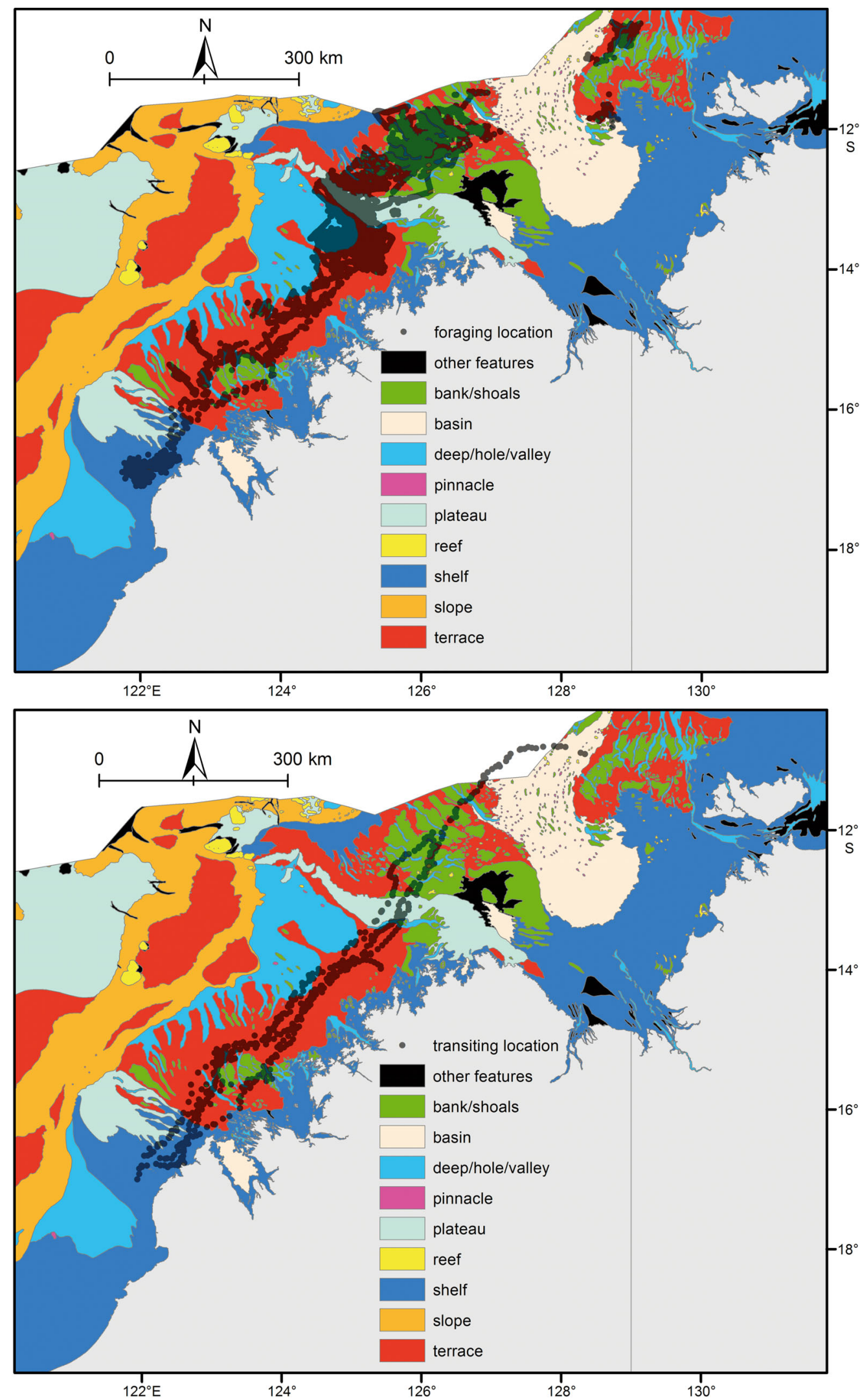

Fig. 5. Geomorphic features overlayed with (a) turtle foraging positions and (b) outward transit positions 

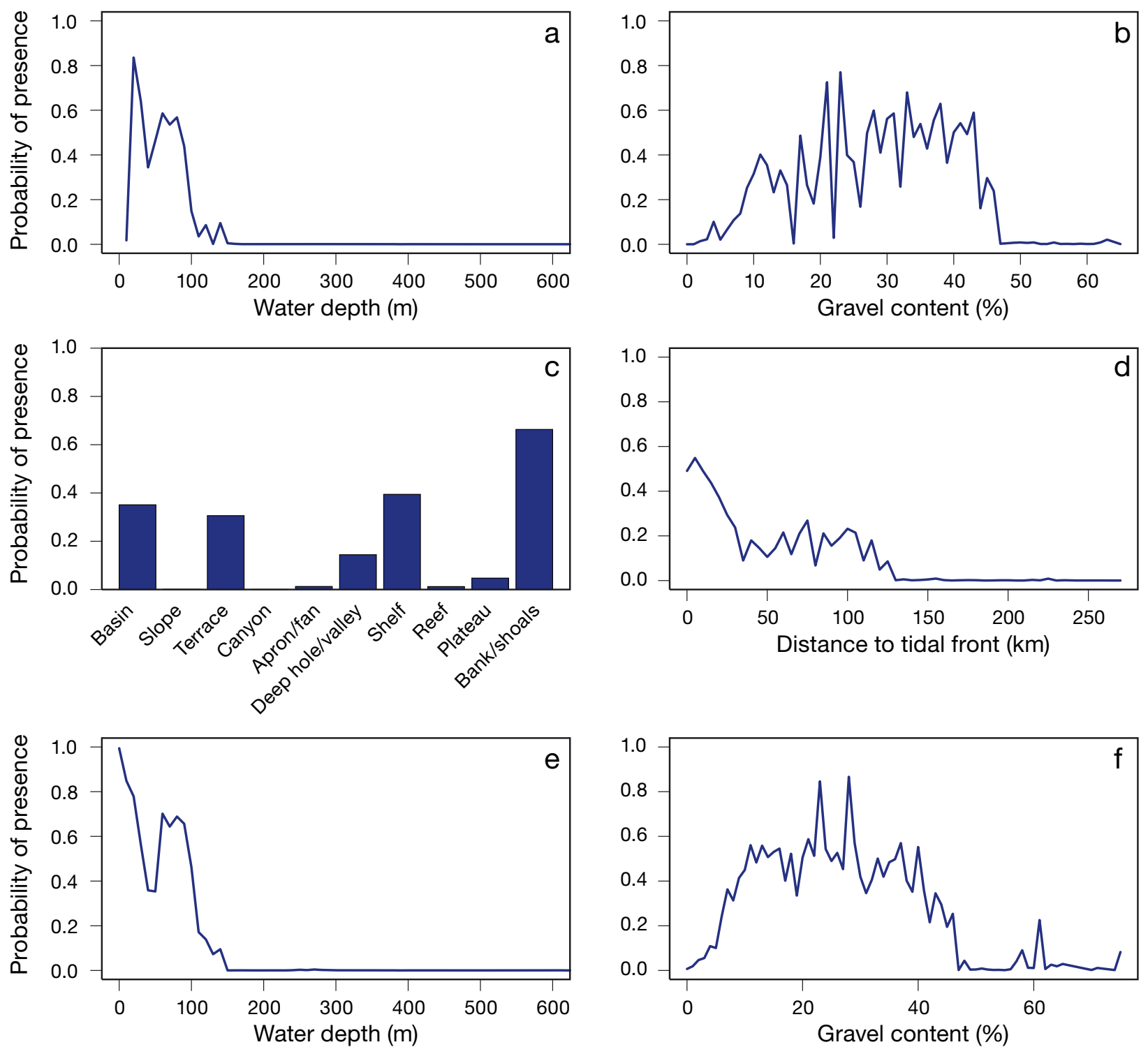

Fig. 6. Response curves for the environmental variables with importance scores $\geq 50$ from the boosted decision tree modelling with pseudo-absences drawn from the offshore modelling domain for (a-d) turtle transit points (presences) and (e,f) turtle foraging points (presences)

the 3 turtles that remained at the islands for foraging $(47671,47679$ and 47689), all of which had low average water depths during this behavioural mode (20, 22 and $14 \mathrm{~m}$, respectively). Another turtle (47680) for which the state-space model failed to detect a switch in behaviour from residency mode also occupied shallow water depths (35 m). The high probability predicted by the model for transiting of turtles in waters of 60 to $90 \mathrm{~m}$ depths matched the average transit depth (grand mean $=63 \pm 5 \mathrm{~m}$ ). Why the turtles should all transit along a similar depth contour is unclear, but might be associated with the presence of the tidal front (see Fig. S3 in the Supplement at www.int-res.com/articles/suppl/ n032p333_supp.pdf), which was identified by the model as an important predictor of turtle presence in transit mode. Many vertebrate marine predators are known to focus their foraging activity within frontal systems (Russell et al. 1999, Polovina et al. 2001, Lea et al. 2002) and some appear to use fronts as migratory pathways (Polovina et al. 2000, 2001). For example, both loggerhead turtles and albacore tuna Thunnus alalunga travel along the transition zone chlorophyll front, a region of convergence that enhances foraging habitat, as they migrate across the North Pacific (Polovina et al. 2000, 2001). While 
the movement behaviour suggests the flatback turtles were mostly not foraging here, they might have been foraging en route.

Alternatively, or in addition, turtles might have been using tidal fronts as aids for navigation to foraging grounds in an otherwise homogeneous ocean (Olson et al. 1994). Although we found that turtles followed a very consistent depth contour during transit, it is unclear how these animals could sense depth, whereas a tidal front would be an obvious boundary between mixed and stratified water, and thus a possible navigational cue for migrating turtles. It is also possible that turtles travelled in association with the tidal fronts to obtain some net benefit of northward movement from the current flow present at this time of the year (summer) along the shelf and slope. If they were diving near to the bottom during transit then perhaps features such as ancient coastlines could also aid navigation. High-resolution multibeam sonar mapping elsewhere on the northwest shelf reveals large-scale structures (ridges and mounds) in $60 \mathrm{~m}$ water depth that are interpreted as drowned shoreline features (Nichol \& Brooke 2011).

On the east coast of Australia (where most studies have been undertaken), flatback turtles are reported to be associated (from records of tag recoveries of turtles captured in prawn trawls) with turbid subtidal soft bottom inshore habitats, mostly within 6 to $35 \mathrm{~m}$ depth, within the Great Barrier Reef (Limpus et al. 2013). While this information is based on qualitative data, our results indicate deeper foraging depths compared to the Great Barrier Reef, with average water depths of $53 \pm 26 \mathrm{~m}$ $(74 \pm 12 \mathrm{~m}$ for the 5 turtles with tracks over $60 \mathrm{~d})$ and turtles located an average of $82 \pm 60 \mathrm{~km}$ from shore $(136 \pm 35 \mathrm{~km}$ for the 5 turtles with tracks over $60 \mathrm{~d})$. Slightly shallower mean water depths were reported for foraging flatback turtles tracked from nesting grounds farther south (Pilbara region of Western Australia) of $36.5 \pm 22.5 \mathrm{~m}$; however, there was a large range (up to $130 \mathrm{~m}$ ), as was the case for foraging distance to shore $(66 \pm 62 \mathrm{~km}$, range $=3$ to $314 \mathrm{~km}$ ) (Whittock et al. 2016). Our model also found a strong association of turtle presence with clear water. The extent of the turbid zone of the Kimberley coastline varies in relation to rainfall events and can extend as far as the $100 \mathrm{~m}$ depth contour, but the boundary between clear and turbid water is generally thought to occur around the $60 \mathrm{~m}$ contour (DEWHA 2007). Based on the available information, it appears that flatback turtles are highly adaptable and are not restricted by water depth or turbidity.
As with other studies on this species (Whittock et al. 2016), the movement behaviour and home range size of individual turtles was highly variable, with 3 turtles remaining around the breeding grounds post nesting, utilising small home range areas (12 to $15 \mathrm{~km}^{2}$ ). In contrast, the other turtles made extensive movements to distant foraging grounds, with home ranges up to 30 times larger. It is unclear why some turtles appear to obtain the resources they need within a small area close to the nesting grounds, whereas others travel to distant foraging grounds; however, this might relate to differing energetic needs (see Schofield et al. 2010) for individuals after the breeding season, and perhaps distant foraging grounds offer a payoff in the form of more predictable and/or profitable resources (Thums et al. 2011). This has implications for the viability of protecting the foraging grounds, which are much larger and have lower overall overlap of individuals than the nesting grounds (Schofield et al. 2010).

A total of 3 turtles provided data greater than $1 \mathrm{yr}$ in duration (450 to $620 \mathrm{~d}$ ) and 2 turtles greater than 2 yr (795 and 831 d) but did not remigrate, suggesting that the remigration interval for flatback turtles here is possibly greater than 2 yr. Remigration intervals for sites farther south were on average 1.6 to 2.2 yr (Pendoley et al. 2014a).

We obtained very limited information on diving patterns of flatback sea turtles from 1 individual over a deployment that only lasted $16 \mathrm{~d}$. This animal spent the majority of its time diving to depths between 50 and $100 \mathrm{~m}$, corresponding with the average water depth recorded under the track $(52 \pm 19 \mathrm{~m})$. This was deeper than the maximum dive recorded for this species of around $44 \mathrm{~m}$ depth (Sperling et al. 2010); however, these earlier data were compiled during the inter-nesting period so were likely constrained by local bathymetry. Dive duration and day-night patterns of diving were consistent with earlier studies, with most dives lasting less than $40 \mathrm{~min}$, and deeper and longer dives occurring during the day than at night.

Although we recorded some of the longest satellite tracks for this species, as with many other tracking studies on marine species, some deployments provided data for only short durations. Suspected reasons for the premature cessation of data uplinks are tag failure, antenna breakage or other damage to the tag, detachment of the harness from the animals and the biofouling of the saltwater switch, which may be particularly problematic in tropical waters (Hays et al. 2007, Meyer et al. 2010). In our 
case, some of the very short durations (16 and $23 \mathrm{~d}$, for example) are likely too short for the effects of biofouling.

There are some limitations of our results, namely the relatively small sample size of tagged animals and that some of the deployment durations did not encompass the entire migration. This would likely influence the calculation of the kernel utilisation distributions, but given that the key areas we defined were similar to those of flatback turtles from other rookeries, we believe that the biologically important areas we identified for the species were valid, at least for adult females (as we did not track males or subadults/juveniles).

While the size and shape of the transmitters used on the turtles suggest no major impacts on their movement (see Jones et al. 2013), the base plate and harness might have increased drag and provided extra surfaces for growth of epibionts. Although a common technique, the impact of the use of harnesses on soft-shelled marine turtles has not been assessed and is an important subject for future research. To this end, it would be useful to compare return rates of flipper tagged turtles between satellite tagged and non-satellite tagged individuals where data are available.

Our analysis suggests that the benthic geomorphology of the mid-Sahul Shelf provides a productive foraging ground for flatback turtles and other turtles within the region. The areas where the turtles forage have been recognised as a key ecological feature by the Australian Government (DSEWPK 1999). While this provides no direct management action it does ensure that environmental impact assessments associated with new developments in the area are informed to take into account any impacts on turtle foraging. The Commonwealth Marine Reserves Network offers additional protection as a 'multiple use zone', and provides the potential for targeted management measures within reserves specifically to protect the turtles. However, only around half of the core foraging area $(50 \%$ utilisation distribution) was encompassed by these reserves. As mentioned above, the size of this area, where the turtles spend the vast majority of their time makes protecting turtle in this area by extending the reserves more difficult than the nesting grounds, without significant impacts on other marine users. Given this difficulty, we suggest that other management actions might be more appropriate (e.g. changes to operating procedures for industry such as vessel speed and routes, reduction in light pollution).
Acknowledgements. This research was partially supported by Browse LNG Development Joint Venture Participants through the operator Woodside Energy Limited. M.T. was supported by an Indian Ocean Marine Research Centre (AIMS/CSIRO/UWA) Collaborative Post-doctoral Fellowship. Part of this work was undertaken for the Marine Biodiversity Hub, a collaborative partnership supported through funding from the Australian Government's National Environmental Science Programme.

\section{LITERATURE CITED}

Bailey H, Shillinger G, Palacios D, Bograd S, Spotila J, Paladino F, Block B (2008) Identifying and comparing phases of movement by leatherback turtles using state-space models. J Exp Mar Biol Ecol 356:128-135

Bailey H, Mate BR, Palacios DM, Irvine L, Bograd SJ, Costa DP (2009) Behavioural estimation of blue whale movements in the Northeast Pacific from state-space model analysis of satellite tracks. Endang Species Res 10:93-106

* Block BA, Jonsen ID, Jorgensen SJ, Winship AJ and others (2011) Tracking apex marine predator movements in a dynamic ocean. Nature 475:86-90

Brewer DT, Lyne V, Skewes TD, Rothlisberg P (2007) Trophic systems of the north west marine region. In: Report to the Department of the Environment and Water Resources. CSIRO, Cleveland

Bustard R (1972) Australian sea turtles: their natural history and conservation. Collins, London

Calenge C (2011) Home range estimation in R: the adehabitatHR package. Office national de la chasse et de la faune sauvage, Saint Benoist

Church JA, Craig PD (1998) Australia's shelf seas: diversity and complexity. In: Robinson AR, Brink KH (eds) The sea. Vol 11. John Wiley and Sons, New York, NY, p 933-964

Cooke SJ (2008) Biotelemetry and biologging in endangered species research and animal conservation: relevance to regional, national and IUCN Red List threat assessments. Endang Species Res 4:165-185

* Costa DP, Robinson PW, Arnould JPY, Harrison AL and others (2010) Accuracy of ARGOS locations of pinnipeds atsea estimated using Fastloc GPS. PLOS ONE 5:e8677

Costa DP, Breed GA, Robinson PW (2012) New insights into pelagic migrations: implications for ecology and conservation. Annu Rev Ecol Syst 43:73-96

D'Adamo N, Fandry C, Buchan S, Domingues C (2009) Northern sources of the Leeuwin Current and the Holloway Current on the North-west Shelf. J R Soc West Aust 2:53-66

DEWHA (Department of the Environment, Water, Heritage and the Arts) (2007) A characterisation of the marine environment of the north-west marine region. In: A summary of an expert workshop convened in Perth, Western Australia, 5-6 September 2007. DEWHA, Canberra

DSEWPC (Department of Sustainability, Environment, Water, Population and Communities) (1999) Marine bioregional plan for the north-west marine region. DSEWPC, Canberra

Dujon AM, Lindstrom RT, Hays GC (2014) The accuracy of Fastloc-GPS locations and implications for animal tracking. Methods Ecol Evol 5:1162-1169

Elith J, Graham CH, Anderson RP, Dudík M and others (2006) Novel methods improve prediction of species' distributions from occurrence data. Ecography 29:129-151 
Haigh ID, MacPherson LR, Mason MS, Wijeratne EMS, Pattiaratchi CB, Crompton RP, George S (2014) Estimating present day extreme water level exceedance probabilities around the coastline of Australia: tropical cycloneinduced storm surges. Clim Dyn 42:139-157

Hays GC (2014) Charismatic marine mega-fauna: some recent discoveries and future challenges. J Exp Mar Biol Ecol 450:1-5

*Hays GC, Bradshaw CJA, James MC, Lovell P, Sims DW (2007) Why do Argos satellite tags deployed on marine animals stop transmitting? J Exp Mar Biol Ecol 349:52-60

Hays GC, Ferreira LC, Sequeira AMM, Meekan MG and others (2016) Key questions in marine megafauna movement ecology. Trends Ecol Evol 31:463-475

Horne JS, Garton EO, Krone SM, Lewis JS (2007) Analyzing animal movements using Brownian bridges. Ecology 88: 2354-2363

Huang Z, Brooke B, Li J (2011) Performance of predictive models in marine benthic environments based on predictions of sponge distribution on the Australian continental shelf. Ecol Inform 6:205-216

* Huang Z, McArthur M, Radke L, Anderson T, Nichol S, Siwabessy J, Brooke B (2012) Developing physical surrogates for benthic biodiversity using co-located samples and regression tree models: a conceptual synthesis for a sandy temperate embayment. Int J Geog Inform Sci 26: 2141-2160

Jones TT, Van Houtan KS, Bostrom BL, Ostafichuk P and others (2013) Calculating the ecological impacts of animal-borne instruments on aquatic organisms. Methods Ecol Evol 4:1178-1186

* Jonsen ID, Myers RA, Flemming JM (2003) Meta-analysis of animal movement using state-space models. Ecology 84: 3055-3063

* Jonsen ID, Flenming JM, Myers RA (2005) Robust statespace modeling of animal movement data. Ecology 86: 2874-2880

Jonsen ID, Basson M, Bestley S, Bravington MV and others (2013) State-space models for bio-loggers: a methodological road map. Deep Sea Res II 88-89:34-46

Kareiva P, Odell G (1987) Swarms of predators exhibit prey taxis if individual predators use area-restricted search. Am Nat 130:233-270

Lea MA, Cherel Y, Guinet C, Nichols PD (2002) Antarctic fur seals foraging in the Polar Frontal Zone: inter-annual shifts in diet as shown from fecal and fatty acid analyses. Mar Ecol Prog Ser 245:281-297

Lefevre J (1986) Aspects of the biology of frontal systems. Adv Mar Biol 23:163-299

* Limpus CJ, Parmenter CJ, Baker V, Fleay A (1983) The flatback turtle, Chelonia depressus, in Queensland: postnesting migration and feeding ground distribution. Aust Wildl Res 10:557-561

Limpus CJ, Gyuris E, Miller JD (1988) Reassessment of the taxonomic status of the sea turtle genus Natator McCulloch, 1908, with a redescription of the genus and species. Trans R Soc S Aust 112:1-10

Limpus CJ, Parmenter CJ, Chaloupka M (2013) Monitoring of coastal sea turtles: gap analysis. 5. Flatback turtles, Natator depressus, in the Port Curtis and Port Alma region. Report produced for the Ecosysytem Research and Monitoring Program Advisory Panel, Gladstone Ports Corporation, Gladstone, QLD

Manel SP, Williams HC, Ormerod SJ (2001) Evaluating presence-absence models in ecology: the need to account for prevalence. J Appl Ecol 38:921-931

*McMahon CR, Bradshaw CJ, Hay GJ (2007) Satellite tracking reveals unusual diving characteristics for a marine reptile, the olive ridley turtle Lepidochelys olivacea. Mar Ecol Prog Ser 329:239-252

Meyer CG, Papastamatiou YP, Holland KN (2010) A multiple instrument approach to quantifying the movement patterns and habitat use of tiger (Galeocerdo cuvier) and Galapagos sharks (Carcharhinus galapagensis) at French Frigate Shoals, Hawaii. Mar Biol 157:1857-1868

Nahas EL, Pattiaratchi CB, Ivey GN (2005) Processes controlling the position of frontal systems in Shark Bay, Western Australia. Estuar Coast Shelf Sci 65:463-474

Nichol SL, Brooke BP (2011) Shelf habitat distribution as a legacy of Late Quaternary marine transgressions: a case study from a tropical carbonate province. Cont Shelf Res 31:1845-1857

Olson DB, Hitchcock GL, Mariano AJ, Ashjian CJ, Peng G, Nero RW, Podesta GP (1994) Life on the edge: marine life and fronts. Oceanography (Wash DC) 7:52-59

Pendoley KL (2005) Sea turtles and the environmental management of industrial activities in north west Western Australia. PhD dissertation, Murdoch University, Perth

*Pendoley KL, Bell CD, McCracken R, Ball KR and others (2014a) Reproductive biology of the flatback turtle Natator depressus in Western Australia. Endang Species Res 23:115-123

* Pendoley KL, Schofield G, Whittock PA, Ierodiaconou D, Hays GC (2014b) Protected species use of a coastal marine migratory corridor connecting marine protected areas. Mar Biol 161:1455-1466

Plummer M (2003) JAGS: A program for analysis of Bayesian graphical models using Gibbs sampling. In: Proc 3rd Int Workshop on Distributed Statistical Computing (DSC 2003)

* Polovina JJ, Kobayashi DR, Ellis DM, Seki MP, Balazs GH (2000) Turtles on the edge: movement of loggerhead turtles (Caretta caretta) along oceanic fronts in the central North Pacific, 1997-1998. Fish Oceanogr 9:71-82

*Polovina JJ, Howell E, Kobayashi DR, Seki MP (2001) The transition zone chlorophyll front, a dynamic global feature defining migration and forage habitat for marine resources. Prog Oceanogr 49:469-483

R Development Core Team (2016) R: a language and environment for statistical computing. R Foundation for Statistical Computing, Vienna

Russell RW, Harrison NM, Hunt GL (1999) Foraging at the front: hydrography, zooplankton and avian planktivory in the northern Bering Sea. Mar Ecol Prog Ser 182:77-93

* Schofield G, Hobson VJ, Lilley MKS, Katselidis KA, Bishop CM, Brown P, Hays GC (2010) Inter-annual variability in the home range of breeding turtles: implications for current and future conservation management. Biol Conserv 143:722-730

Silverman BW (1986) Density estimation for statistics and data analysis. Chapman and Hall, London

Simpson JH (1981) The shelf-sea fronts - implications of their existence and behaviour. Philos Trans R Soc Lond A 302:531-546

* Simpson JH, Hunter JR (1974) Fronts in the Irish Sea. Nature 250:404-406

Sperling JB, Guinea ML (2004) A harness for attachment of satellite transmitters on flatback turtles. Mar Turtle Newsl 103:11-13

Sperling JB, Grigg GC, Limpus CJ (2010) Diving behaviour 
in two distinct populations of gravid flatback turtles Natator depressus. Aust Zool 35:291-306

Thums M, Bradshaw CJ, Hindell MA (2011) In-situ measures of foraging success and prey encounter reveal marine habitat dependent search strategies. Ecology 92: 1258-1270

Van Andel TH, Veevers JJ (1965) Submarine morphology of the Sahul Shelf, northwestern Australia. Geol Soc Am Bull 76:695-700

Waayers DA, Smith LM, Malseed BE (2011) Inter-nesting distribution of green Chelonia mydas and flatback turtles Natator depressus at the Lacepede Islands, Western Australia. J R Soc West Aust 94:59-64

Waayers DA, Mau R, Mueller A, Smith JE, Pet-Soede L (2015) A review of the spatial distribution of marine turtle nesting and foraging areas in Western Australia. In: Whiting SD, Tucker A (eds) Proc 2nd Western Australian

Editorial responsibility: Paolo Casale, Rome, Italy marine turtle symposia. Science Division, Department of Parks and Wildlife, Perth, p 83-86

Wand MP, Jones MC (1995) Kernel smoothing. Chapman and Hall, London

*Whiting SD, Long JL, Coyne M (2007) Migration routes and foraging behaviour of olive ridley turtles Lepidochelys olivacea in northern Australia. Endang Species Res 3:1-9

Whittock PA, Pendoley KL, Hamann M (2014) Inter-nesting distribution of flatback turtles Natator depressus and industrial development in Western Australia. Endang Species Res 26:25-38

* Whittock PA, Pendoley KL, Hamann M (2016) Flexible foraging: post-nesting flatback turtles on the Australian continental shelf. J Exp Mar Biol Ecol 477:112-119

Zangerl R, Hendrickson LP, Hendrickson JR (1988) A redescription of the Australian flatback sea turtle, Natator depressus. Bishop Mus Bull Zool 1:1-69

Submitted: October 13, 2016; Accepted: February 14, 2017 Proofs received from author(s): April 11, 2017 